\title{
Telecollaboration for Civic Competence and SDG Development in FL Teacher Education
}

\author{
Soraya Garcia-Esteban
}

Universidad de Alcalá

\section{Abstract}

The Civic Competence has been acknowledged essential to support sustainable societies, economies and ecosystems for the development of responsible active citizens in today's increasingly connected world. In this regard, telecollaboration seems to help enhance related media literacy and intercultural skills. However, despite the development of key competences for lifelong learning with telecollaboration has already been the focus of some studies, the measurement of Civic Competence in teacher education with telecollaboration remains still a question for investigation. Following this line of research, this study aimed to explore the own perception of FL student teachers in Civic Competence, and if this competence can be developed working the Sustainable Development Goals (SDG) with telecollaboration. The participants of this study were two groups of student teachers at two different European universities. Both groups completed a survey and proposed collaborative strategies to improve the global and Civic Competence. Educational proposals and digital collaborative tools were analysed to measure the improvement of the student teachers' perception. Forum, e-portfolios and evaluation forms together with pre- and postquestionnaires were used to explore the outcomes. Results indicated that most Civic Competence domains can be enhanced by working SDG and that adopting a reflective, experiential and safe collaborative online international learning approach can help promote further knowledge, skills and attitudes in specific contexts.

Keywords: telecollaboration, civic competence, global competence, sustainable development goals (SDG), FL teacher training

\section{Introduction}

This study documents a pedagogical research developed in the second term of 2020 by two European universities. Based on data from a small-scale pilot research, we obtained some initial evidence that, by providing future teachers with educational collaborative technology, we can improve education in Civic Competence (EC 2018, 2019) and Sustainable Development Goals (OECD 2018). 
Education in citizenship has clearly gained prominence in national curricula across Europe at all levels. Despite terminology varies and Social and Civic Competences have been largely included in several frameworks, the Social and Civic Competences can be grouped together as one competence as described in the current European Commission suggested framework (EC 2018). As defined by the OECD (2018), the Civic Competence relates to the Global Competence and comprises Global Mindedness, the ability to interact respectfully, appropriately and effectively as well as the Knowledge and understanding of global issues. Education can help make citizens contribute to peaceful, tolerant, inclusive and secure societies (2018:24).

Despite some research has acknowledged the cultural significance of Citizenship values in teacher training (Chistolini 2019), literature calls for a development of the intercultural dimension, together with critical thinking, active democratic participation and sustainable development (EC 2018:34). This can be developed integrating the Sustainable Development Goals (SDG) in the curriculum to promote "knowledge, skills and attitudes related to sustainable development and lifestyles, human rights, gender equality, promotion of a culture of peace and non-violence, global citizenship and appreciation of cultural diversity through education" (UN 2015, OCDE 2018).

\section{Literature Review}

Based on existing literature of teaching and learning theories on sustainability (i.e. Mindt and Rieckman 2017) and further research on key competencies for sustainable development in higher education (i.e. Barth, Godemann, Rieckmann and Stoltenberg 2007), this study has considered studies (i.e. Schwarzer and Bridglall 2015) that focused on promoting specific domains that link the Global with the Civic Competence in teacher education. According to the OECD, it is crucial to offer students the opportunity to learn about global developments and to teach how to form a critical and realistic vision of current affairs, contributing instruments of analysis of diverse cultural practices, involving students in intercultural relations, as well as promoting the value of diversity (2018). However, there are few academic studies that confirm the appropriate acquisition of civic knowledge, skills and attitude with SDG following a specific validated framework or specific pedagogies.

Although one of the priorities of organizations such as UNESCO and the European Council is to evaluate the acquisition of key competences for permanent learning (EC 2018) with digital resources, there are still few studies that ratify the appraisal of citizenship in collaborative online environments (Vinagre 2016). This research proposal takes as a starting point previous investigation projects on the acquisition of competences and skills with communicative online collaboration, virtual exchange and telecollaboration in English mediated instruction (ie. VELCOME, TELNETCOM, TILA, UniCollaboration, TeCoLa) following Colpaert (2020). Findings highlight telecollaboration for intercultural and content integrated language teaching and indicate that participants who use telecollaboration to develop competences for 
lifelong learning can improve their technological pedagogical content knowledge and the learning to learn competence (Garcia-Esteban, Villarreal and Bueno 2018, 2019), social skills in task-based language learning and teaching (Hauck 2010) and the digital competence (González-Lloret, 2013). Related research can be found in online intercultural exchange and the development of transnational models of virtual exchange for global citizenship education (O'Dowd 2020), the enhancement of soft skills in higher education foreign language programs with telecollaboration (Gomez, 2019) or the need to develop basic, digital and cognitive skills for professional development (Garcia and Jahnke 2020).

This study is based on Dörnyei's (2013) seven principles for effective communication in the foreign language and Tondeur's (2018) approach for the development of future teachers' competencies with technology integration. It is also founded on Guth and Helm's (2010) pedagogy, which considered that telecollaboration facilitates foreign language (FL) teaching with digital tools and online communication with peers mainly to develop language skills, digital and communicative competences (Dooly 2008, Ware and Kramsch 2005) as well as competences for life-long learning such as the Civic Competence.

The research attempts to contribute to educational innovation by filling an existing gap in terms of evaluating the perceptions in Civic Competence following the EC (2019) framework of multilingual postgraduate student-teachers and the proposal of didactic practices for improvement of the less developed domains with telecollaboration.

\section{Methodology}

\subsection{Participants and instruments}

This study included Masters' degree participants from the disciplines of Education and Humanities from two European Universities: on in the center of Spain $(n=23)$, which was the experimental group (EG), and a Belgian University $(\mathrm{n}=18)$ taken as control group (CG). The majority of the participants in the survey were multilingual females who had been studying, living or visited more than one European country. Both Master programs followed the (ECTS) European Credit Transfer and Accumulation System.

The program offered by the Belgian University was an Educational Master from the Department of Linguistics. The participants from this university were 18 participants enrolled in the specific course "English linguistics, Arts and literature". The course was designed to be delivered face to face and involved working digital collaborative tools such as the institutional learning platform Blackboard, and the use of social media for research purposes, etc. The course followed a subject-specific pedagogy which covered student diversity and guidance. 
The participants from the Spanish university were 23 student teachers from the Master's Degree in Teacher Training, English specialization, enrolled in the course "Content and Language Integrated Learning in the Bilingual Classroom" as part of the Master's Degree in Secondary Education Teacher Training. The subject was taught online following a content and language integrated learning approach. This master degree was part of the Department of Modern Philology.

The experimental group was proposed a collaborative online task consisting on researching educational materials to design a lesson plan based on a given content topic for native English speakers on the web relating contents to a SDG which might help develop certain domains of the SDG Global Competence (OECD 2020, 2018) and the Civic Competence (EC 2019). This task was delivered online and was built on the pedagogy of telecollaboration (Dooly, 2008, Guth and Helm 2010), which involved incorporating several online collaborative tools: videoconferencing and discussion Forum through the institutional learning platform (Blackboard), Social media (YouTube, Google+, Academia.edu) and collaborative Web apps (Padlet). Figure 1 Illustrates this task with the lesson plans designed and evaluated collaboratively by the student teachers.

Figure 1. UAH- ODS Lesson Plans Padlet

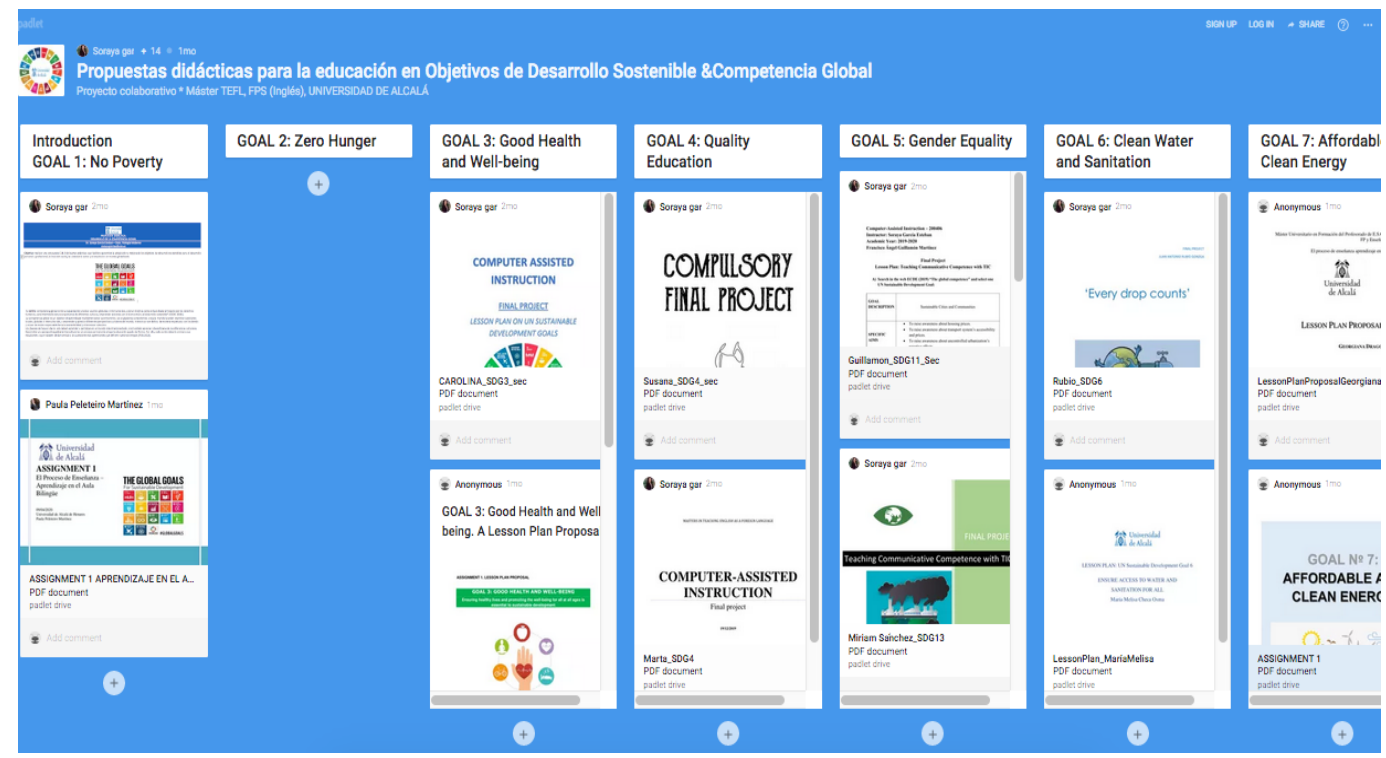

This tasks was based on Dörnyei's (2013) seven principles for effective communication in the foreign language, which consider that learning should be meaningful and engaging; tasks should allow controlled practice; vocabulary and grammar should often appear in different types of tasks, there should be a balance between both fluency and accuracy in the syllabus design, when carrying out communicative tasks students should also practice formulaic language, students 
should be exposed to the foreign language constantly and interaction between students should take place in all communicative activities.

\subsection{Method and data collection}

The proposed research unit of qualitative nature consisted of an exploratory descriptive study, using as an instrument the open or in-depth survey with a medium level of directivity, semi-structured as to which some open-ended questions were raised so that the participants could freely express their ideas, beliefs, opinions, assessments (Tójar 2006). We chose to use the survey because it offered the participant the possibility to comment on the questions (Rodríguez Gil \& García 1996) following the Test-Retest method in order to identify possible changes and improvements. We deployed student and teacher surveys among all the MA participants and collected data over the second term course along six months. Teacher surveys included open answer questions relating to teachers' professional development opportunities and their existing perceptions of the Civic and Global Competences. We incorporated the findings from these interviews into our qualitative data.

Following Hinton (2019), in our initial analyses we utilized qualitative methods to categorize and codify the participant responses. This enabled a general understanding of the learning activities with respect to sets of competencies, which provided us with context for subsequent analyses of the data. We used methods adapted from Grounded Theory. With this approach, we systemized participants' ideas by organizing them into codes through two main steps: substantive coding and selective coding. First, the data were substantively coded, which involves coding all of the data for meaning. These codes were condensed versions of the participants' ideas. These substantive codes were then analysed to create selective codes using a combination of deductive and inductive processes. That is, substantive codes were logically combined based on both frameworks from academic literature on global education and themes that deductively emerged from the data.

\section{Results}

Data exploration in this study consisted on an online questionnaire based on OECDE (2018) Global Competence which enclosed sub-domains from the SDG (OECD 2019) and the domains illustrated in Table 1 from EC (2019) Civic Competence. Quantitative analysis of student teachers' survey data aimed to identify participants' perceptions before and after working the SDG assignment with digital collaborative tools. Focused qualitative analyses of open response survey data allowed to explore relationships between collaborative Educational Technology and the Civic Competence.

To carry out the investigation, we correlated OECDE (2018) Global Competence construct with EC (2019) Civic Competence participants' perceptions. The table below presents the results after having worked the Global Competence developing lesson plans for teaching a particular subject in English as a foreign language using 
diverse methodologies integrating the 17 Sustainable Development Goals (SDG) as subject contents. Scores were standardized based on all responses in the survey so that scores have a mean of 0 and standard deviation of 1 . The relative magnitude of the Civic Competence scores had a meaningful interpretation.

Table 1. FL Student teachers' perceptions of the Civic Competence (EC 2019)

\begin{tabular}{|c|c|c|c|c|}
\hline Knowledge & $\begin{array}{c}\text { EG } \\
\text { Pre- } \\
\text { test }\end{array}$ & $\begin{array}{c}\text { EG } \\
\text { Post- } \\
\text { test }\end{array}$ & $\begin{array}{l}\text { CG } \\
\text { Pre- } \\
\text { Test }\end{array}$ & $\begin{array}{c}\text { CG } \\
\text { Post- } \\
\text { Test }\end{array}$ \\
\hline 1. Knowledge of basic concepts/phenomena relating to individuals, groups, work organizations, society, economy and culture & $52 \%$ & $67 \%$ & $57 \%$ & $61 \%$ \\
\hline 2. Understanding of the European common values & $27 \%$ & $27 \%$ & $38 \%$ & $34 \%$ \\
\hline 3. Knowledge of contemporary events & $67 \%$ & $83 \%$ & $73 \%$ & $74 \%$ \\
\hline 4. Critical understanding of the main developments in national, European and world history & $48 \%$ & $46 \%$ & $54 \%$ & $58 \%$ \\
\hline 5. Awareness of the aims, values and policies of social and political movements & $66 \%$ & $65 \%$ & $77 \%$ & $69 \%$ \\
\hline 6. Awareness of sustainable systems; ex. climate and demographic change at global level and underlying causes & $70 \%$ & $83 \%$ & $67 \%$ & $68 \%$ \\
\hline 7. Knowledge of European integration & $67 \%$ & $64 \%$ & $67 \%$ & $71 \%$ \\
\hline 8. Awareness of diversity and cultural identities in Europe and the world & $55 \%$ & $77 \%$ & $68 \%$ & $68 \%$ \\
\hline 9. Understanding of the multi-cultural and socioeconomic dimensions of European societies & $48 \%$ & $56 \%$ & $65 \%$ & $73 \%$ \\
\hline 10. Understanding of how national cultural identity contributes to the European identity & $75 \%$ & $83 \%$ & $77 \%$ & $78 \%$ \\
\hline \multicolumn{5}{|l|}{ Skills. } \\
\hline 11. Ability to engage effectively with others in common or public interest, including sustainable development of society & $52 \%$ & $83 \%$ & $54 \%$ & $50 \%$ \\
\hline 12. Critical thinking and integrated problem solving skills & $58 \%$ & $57 \%$ & $48 \%$ & $58 \%$ \\
\hline 13. Skills to develop arguments and constructive participation in community activities & $45 \%$ & $83 \%$ & $48 \%$ & $73 \%$ \\
\hline 14. Decision-making at all levels, from local and national to the European and international level & $37 \%$ & $40 \%$ & $48 \%$ & $44 \%$ \\
\hline 15. Ability to access, have a critical understanding of, and interact with both traditional and new forms of media & $63 \%$ & $72 \%$ & $54 \%$ & $63 \%$ \\
\hline 16. Understanding the role and functions of media in democratic societies & $78 \%$ & $77 \%$ & $75 \%$ & $41 \%$ \\
\hline \multicolumn{5}{|l|}{ Attitudes } \\
\hline 17. Respect for human rights as a basis for democracy & $73 \%$ & $83 \%$ & $72 \%$ & $73 \%$ \\
\hline 18. Responsible and constructive attitude & $77 \%$ & $82 \%$ & $82 \%$ & $78 \%$ \\
\hline 19. Constructive participation in democratic decision-making at all levels and civic activities & $48 \%$ & $42 \%$ & $54 \%$ & $50 \%$ \\
\hline 20. Support for social and cultural diversity, gender equality and social cohesion, sustainable lifestyles & $67 \%$ & $77 \%$ & $62 \%$ & $69 \%$ \\
\hline 21. Promotion of culture of peace and non-violence & $68 \%$ & $76 \%$ & $67 \%$ & $73 \%$ \\
\hline 22. Readiness to respect the privacy of others & $80 \%$ & $82 \%$ & $72 \%$ & $70 \%$ \\
\hline 23. Responsibility for the environment & $73 \%$ & $92 \%$ & $79 \%$ & $82 \%$ \\
\hline 24. Interest in political and socioeconomic developments, humanities and intercultural communication & $57 \%$ & $68 \%$ & $72 \%$ & $78 \%$ \\
\hline 25. Preparation both to overcome prejudices and to compromise where necessary and to ensure social jus & $45 \%$ & $52 \%$ & $54 \%$ & $50 \%$ \\
\hline
\end{tabular}

As illustrated in table 1, results concerning the knowledge dimension indicated that the experimental group (EG) increased their perception in Knowledge of basic concepts and phenomena relating to individuals, groups, work organizations, society, economy and culture (from 52\% to 67\%) after working the SDG with collaborative tools. The task proposed also helped enhance their knowledge of contemporary events (from $67 \%$ to $83 \%$ ) and their awareness of sustainable systems such as climate and demographic change at global level and underlying causes (from $70 \%$ to $83 \%$ ). Working SDG seemed to help understand the multi-cultural and socioeconomic dimensions of European societies (from 48\% to 56\%) and how national cultural identity contributes to the European identity (from 75\% to 83\%).

Regarding the skills dimension, data revealed that the telecollaborative task seemed to increase the EG ability to engage effectively with others in common or public interest, including sustainable development of society (from $52 \%$ to $83 \%$ ), as well as skills to develop arguments and constructive participation in community activities (from $45 \%$ to $83 \%$ ). Gains were also observed in the EG ability to access, have a 
critical understanding of, and interact with both traditional and new forms of media (from $63 \%$ to $72 \%$ ).

EG Student teachers attitudes also experienced an upgrade in domains such as respect for human rights as a basis for democracy (from $73 \%$ to $83 \%$ ), and responsible and constructive attitude (from $77 \%$ to $82 \%$ ) working SDG collaboratively. The experiential task seemed to contribute to support social and cultural diversity, gender equality and social cohesion, sustainable lifestyles (from $67 \%$ to $77 \%$ ); the promotion of culture of peace and non-violence (from $68 \%$ to $76 \%$ ) and readiness to respect the privacy of others (from $80 \%$ to $82 \%$ ) showing a sharp growth in responsibility for the environment (from $73 \%$ to $92 \%$ ). However, the upturn interest in political and socioeconomic developments, humanities and intercultural communication (from $57 \%$ to $68 \%$ ), and the preparation both to overcome prejudices and to compromise where necessary to ensure social justice and fairness (from $45 \%$ to $52 \%$ ) were not noteworthy.

Figure 2. Comparison of student teachers' perception of the Civic Competence after the SDG telecolaboration task

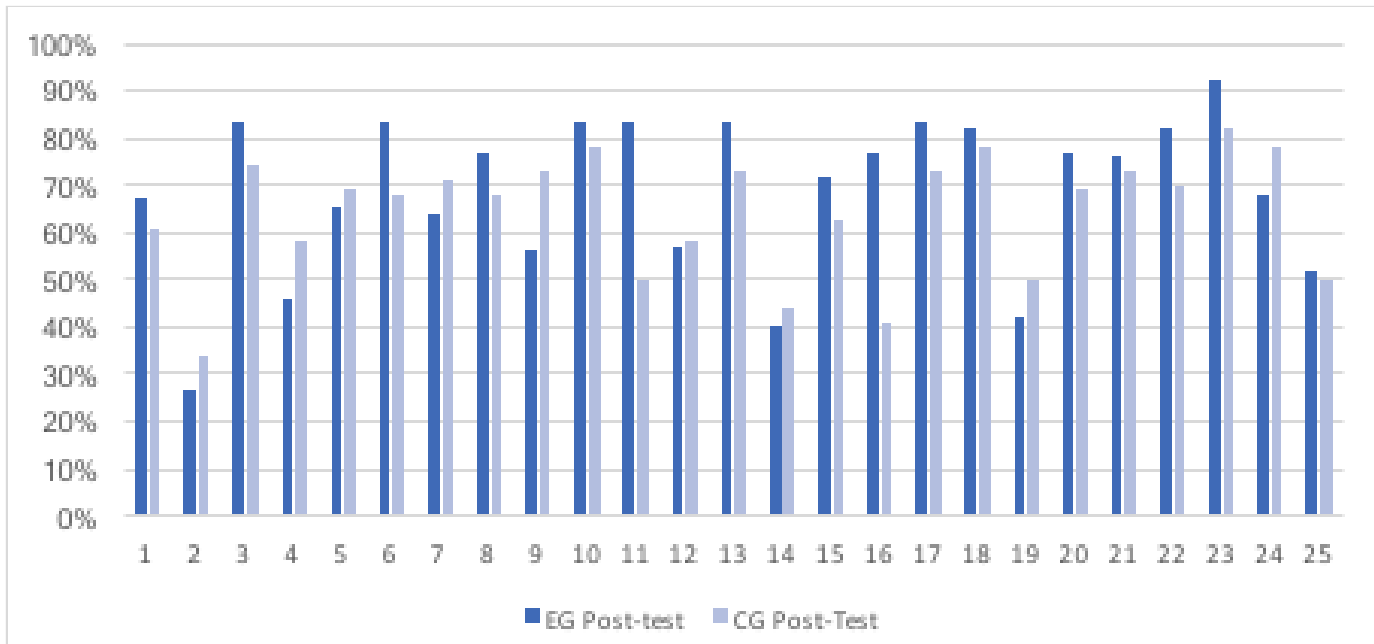

Data outcomes in Figure 2 showed that working SDG with telecollaboration increased slightly the 16 dimensions of the Civic Competence labelled above, except for 9 competences in which the CG rated higher after the experiential task. These were: understanding of the European common values (34\% against 27\%), critical understanding of the main developments in national, European and world history (58\% against 46\%); awareness of the aims, values and policies of social and political movements (69\% against 65\%); Knowledge of European integration (71\% against 64\%); critical thinking and integrated problem solving skills (58\% against 57\%), decision-making at all levels, from local and national to the European and international level (44\% against 40\%); understanding the role and functions of media 
in democratic societies ( $41 \%$ against $77 \%$ ), and constructive participation in democratic decision-making at all levels and civic activities (50\% against $42 \%$ ).

\section{Analysis and discussion}

Despite the EG rated higher after having carried out the experimental task, outcomes show that differences in perceptions among the two groups in different European locations cannot be considered significant. Possible reasons can be the CG educational curricula, which developed cultural and historical contents, the teaching methodology, and the location of their university in the centre of Europe. These contextual factors might have influenced the perception of the CG participants as a possible explanation for their interests in the European topics where they rated higher. Furthermore, it must be noted that the EC (2019) framework of the Civic Competence used in this research comprise European issues whereas de SDG (OECD 2018) framework focuses on worldwide concerns, which might not have helped develop specific dimensions related to this continent.

The following lines relate the outcomes with research on the Civic Competence and telelecollaboration. Data was examined to explore learning activities that can be effective in promoting the Civic Competence, considerations for implementing them effectively with telecollaboration and possible challenges. To provide further context to our analyses, student teachers' responses have been transcribed in italics.

Findings have revealed that proposing FL student teachers a task consisting on the design of a lesson plan associated to a specific SDG to teach contents of a particular area (History, Geography, Art, etc.) with online collaborative resources contributes to the development of their Civic Competence as sustainable development "include participatory and collaborative skills; interdisciplinary and intercultural understanding; the ability to reflect on one's own position and take different perspectives; effective communication; critical reflection; initiative-taking and problem-solving; taking responsibility; empathy, compassion and solidarity (EU 2018:41).

Data seem to indicate that the overall student teachers' level of Civic Competence scored over in those participants who had worked the online SDG assignment with collaborative tools except for 9 of the 25 domains or competencies (CC $2,4,5,7,12,14,16,19,22$ ). Differences in the results between the CG and EG coincide with the domains that correlate directly with the OECD (2018) Sustainable Development Goals, specifically: basic human rights, climate change and environmental issues, sustainable development and social inclusion and active citizenship. Higher scores can be attributed to the participants who worked them in class. The lines below describe the proposals to develop the domains with a telecollaborative approach.

Overall, the three dimensions evaluated in this study: Knowledge, Skills and Attitudes, were enhanced working the SDG and relating them to specific contents of the study 
program. For this, effective educational methods needed to be used following Mezirow's (1997) transformational learning for deep, constructive and meaningful learning. This can be achieved with discussions related to the SDG through Project Based Learning (PBL) and Task based learning (TBL) with telecollaborative tools (eg. Forums or discussion Chats) on a learning platform (ex. Blackboard, Teams, etc.) as revised by Hauck (2010).

knowledge about global citizenship "has to be combined with practice, actual experiences and opportunities for learners to develop, test and build their own views, and to learn how to take actions responsibly. Participation in community activities and opportunities to interact with other populations of different backgrounds or views are necessary" (EC 2018:51). This dimension could be enhanced setting telecollaboration tasks with external organizations (ex. NGO) or collaboratively with other Higher Education Institutions, following O'Dowd and Lewis (2016) in order to enhance less developed domains such as Understanding of the European common values (CC2), Critical understanding of the main developments in national, European and world history CC4), or Knowledge of European integration (CC7). Areas such as Awareness of the aims, values and policies of social and political movements (CC5) could be developed using internet and social media to research different situations or societal issues, and working online contents from internet (news/documentaries/issues) in collaborative online discussion tasks as described by Rubin and Guth (2016).

Regarding Civic Competence skills, critical thinking, decision-making and problem solving have been considered the most important ones (EC 2018:35, Garcia and Jahnke 2020). Outcomes have shown that working the SDG with a telecollaborative approach helps develop arguments and community participation in constructive activities using collaborative tools such as discussion forums or collaborative Web apps (Padlet) for co-evaluation.

Data seem to indicate that telecollaboration also facilitates "Education for Sustainable Development with a significant impact on raising awareness and developing curricula, teaching material and partnerships for learning on sustainable development" (EC 2018: 98), thus allowing participants to engage effectively with others in common interests, including sustainable development of society and developing arguments. Working SDG can help develop these skills by proposing the writing of collaborative tasks using online repositories, carrying out projects sharing files with other students or promote critical argumentation in co-evaluations with collaborative programs such as Comproved. However, there are still difficulties to find online learning platforms in which all these functionalities are jointly available.

However, results show that some skills still need to be developed. Critical thinking and integrated problem solving skills (CC12), could be enhanced proposing Mezirow's (1997, 2000) experiences of disorientation dilemmas. Similarly, decision-making at all levels, from local and national to the European and international level (CC14) could be enhanced working PBL and TBL by creating and 
sharing short videos on topics related to the SDGs to be further discussed in social media. Understanding the role and functions of media in democratic societies (CC16) could be developed with training in strategies to search and analyze information from Internet critically.

Civic Competence attitudes "highlight the role of citizenship, democratic values (CC19) and human rights in todays increasingly connected global societies. Understanding of the need to support sustainable societies, economies and ecosystems, as well as practice sustainable lifestyles is a key element of this competence" (EC 2018:39). Therefore, teachers are expected to build on responsible, active citizenship to contribute to peaceful, tolerant, inclusive and secure societies. In this context, media literacy and intercultural skills can be further strengthened with telecollaboration (Dooly 2008). This can be achieved developing SDG contents with multimedia tools. Digital animation allows students to edit movies and present them collaboratively with Storify, Prezi, Storymaker, Mindnote, Flipgrid, Buncee, or Padlet (fig. 1) ensuring the respect and privacy of others.

\section{Conclusions}

This research has provided accounts of how the Civic Competence can be enhanced working the SDG with diverse collaborative online learning resources and methods. For that purpose, we explored the perception and proposals of two groups of multilingual and multicultural MA student-teachers from different European universities. Results indicated that the participants who worked the SDG following a telecollaboration approach rated slightly higher in most of the Civic Competence domains, but both groups declined in those competences which were interwoven with active citizenship. Proposals for improvement underscored reflective appraisal in safe digital media and experiential telecollaboration with external institutions, thus following a collaborative online international learning approach.

According to the study carried out, working the SDG following a telecollaboration pedagogy seems to contribute to the development of Civic Competence since it fosters the adoption of a multiple approach to promote civic awareness, critical thinking, FL communicaive skills and collaborative learning, which leads to a better understanding of world views, norms and values. Although telecollaboration has been acknowledged to facilitate intercultural communicative competence, which might be the reason of the high rates scored by the participants in related domains, the novelty of this study is the appraisal of the participants' perceptions following a validated framework of the Civic Competence with proposals for the integration of the SDG in higher education. The current teaching approaches revised in the study can be adapted to various learning environments.

Data seem to confirm that telecollaboration not only can help develop the Civic Competence and the SDG but it can also enhance Dörnyei's (2013) seven principles for effective communication. An exception took place in the formulaic language 
principle, which involved using structures as they are used for communication in real life. This could be facilitated in virtual exchanges with external organizations or integrating real experiences abroad. Although the main approach is meaningoriented, teachers should also make sure that the focus-on-form principle is met by promoting critical thinking.

This study has explored the development of the Civic Competence integrating the SDG with telecollaboration in the teaching program of a sample of multilingual European student teachers with the final aim to identify needs and proposals for improvement. However, some shortcomings should be acknowledged and results should be taken with caution. First, further research is required for a detailed analysis of the underlying causes of upgrading or shortcomings in Civic Competence in order to adjust each teaching program and collaborative task to the specific needs. Second, it should be analysed whether a different type of SDG task would produce similar results. Third, a proper validation of the enhancement of the Civic Competence with telecollaboration with a wider sample would be needed. Additionally, the correlation between the SDG and the Civic Competence domains is still under-researched by academics and should be addressed as future direction for investigation. Recommendations point out the need for providing future FL teachers with further educational collaborative technology resources and methods to enhance the less developed sustainable developed areas and goals. This could be assured incorporating the SDG in the curriculum following Colpaert's transdisciplinary approach and with the use of Open Data "where it all comes together": technology, education, policy, production, linguistics and thinking (2018:11).

Despite the findings might vary in different contexts, we believe that along this study, (future) educators have been empowered with the SDG and Civic Competence appraisal experience by reflecting upon their own development, which nonetheless contributes to the qualification of future citizens for a more sustainable world.

This project was supported by the Spanish Ministry of Economy and Competitiveness [grant number: RTI2018-094601-B-100].

\section{References}

[1] Barth, M.; Godemann, J.; Rieckmann, M. \& Stoltenberg, U. (2007) Developing key competencies for sustainable development in higher education.

International Journal of Sustainability in Higher Education, 8 (4), 416-430. https://doi.org/10.1108/14676370710823582.

[2] Bueno-Alastuey, M. C., Villarreal, I., \& García Esteban, S. (2018). Can telecollaboration contribute to the TPACK development of pre-service teachers?. Technology, Pedagogy and Education, 27 (3), 1-14.

[3] Chistolini, S. (2019). Citizenship Education and Teacher Training. Research and Practice in Italy. European Journal of Education 2(3):51. DOI: 10.26417/ejed.v2i3.p51-63. 
[4] Colpaert, J. (2018). Exploration of Affordances of Open Data for Language Learning and Teaching, Journal of Technology and Chinese Language Teaching 9 (1), 1-14.

[5] Colpaert, J. (2020). Editorial position paper: how virtual is your research?, Computer Assisted Language Learning, 33:7, 653-664, DOI:

10.1080/09588221.2020.1824059

[6] Dörnyei, Z. (2013). Communicative language teaching in the twenty-first century: The principled communicative approach, in J. Arnold \& T. Murphey (Eds.), Meaningful action: Earl Stevick's influence on language teaching (pp. 161-171). Cambridge: Cambridge University Press.

[7] Dooly, M. (ed.) (2008). Telecollaborative language learning. Moderating intercultural collaboration and language learning. A guidebook to moderating intercultural collaboration online. Bern: Peter Lang.

[8] EC, European Commission (2019). Key Competences for Lifelong learning. Luxembourg: Directorate-General for Education, Youth, Sport and Culture (European Commission). Doi. 10.2766/569540

[9] García Esteban, S., Jahnke, S. (2020). Skills in European Higher Education Mobility Programmes: Outlining a Conceptual Framework. Higher Education, Skills and Work-Based Learning. 10 (3), pp. 519-539. https://doi.org/10.1108/HESWBL-09-2019-0111.

[10] García-Esteban, S., Villarreal, I. Bueno-Alastuey, M.C. (2019). The effect of telecollaboration in the development of the learning to learn competence in CLIL teacher training. Interactive Learning Environments, 27 (5-6). DOI: 10.1080/10494820.2019.1614960.

[11] González-Lloret, M. (2013). Technologies for performance-based assessment. In Competency-based language teaching in Higher Education, pp. 169-184. Amsterdam: Springer.

[12] Hauck, M. (2010). The enactment of task design in tellecollaboration 2.0. In M. Thomas \& H. Reinders (Eds.) Task-based language learning and teaching with technology, pp. 197-217. London: Continuum.

[13] Hinton, C. coord. (2019). Developing Students' Global Competence - An International Research Study. Round Square, Available at https://www.roundsquare.org/wp-content/uploads/2019/11/RS-RSIGlobal-Competence-Report_13-11-19.pdf.

[14] Mezirow, J. (1997). Transformative Learning: Theory to Practice. New Directions for Adult and Continuing Education. 74, 5-12. doi:10.1002/ace.7401

[15] Mindt, L. \& Rieckman, M. (2017). Desarrollo de las competencias para el emprendimiento orientado a la sostenibilidad en la educación superior: una revisión bibliográfica de los métodos de enseñanza y aprendizaje. Teoría De La Educación. Revista Interuniversitaria, 29(1), 129-159.

doi:10.14201/teri.16702. 
[16] OECD (2018). Preparing our youth for an inclusive and sustainable world. The OECD PISA Global Competence framework. París. OECD Publishing. Available at: https://www.oecd.org/pisa/Handbook-PISA-2018-GlobalCompetence.pdf

[17] Rubin, J. \& Guth, S. (2016) Collaborative Online International Learning: An emerging format for internationalizing curricula. In A. Schultheis Moore \& S. Simon (eds) Globally Networked Teaching in the Humanities: Theories and Practices. London/New York: Routledge, 15-27.

[18] Schwarzer \& B. L. Bridglall (2015), Promoting Global Competence and Social Justice in Teacher Education: Successes and Challenges Within Local and International Contexts. NY: Lesington Books.

[19] O'Dowd, R. (2020). A transnational model of virtual exchange for global citizenship education. Language Teaching, 53(4), 477-490. doi:10.1017/S0261444819000077.

[20] Tondeur, J. (2018). Enhancing future teachers' competencies for technology integration in education: Turning theory into practice. Seminar.net, 14(2), 216-224. Available at https://journals.hioa.no/index.php/seminar/article/view/2981

[21] Vinagre, M. (2016). Developing key competences for life-long learning through virtual collaboration: Teaching ICT in English as a Medium of Instruction. In Wang, P. \& Winstead, L. Handbook of Research on Foreign Language Education in the Digital Age. 170-187. 